\title{
"Highly processed, highly packaged, very unhealthy. But they are low risk": exploring intersections between community food security and food safety
}

\author{
Kelsey A. Speed, MSc; Samantha B. Meyer, PhD; Rhona M. Hanning, PhD; Shannon E. Majowicz, PhD
}

This article has been peer reviewed.

Tweet this article

\begin{abstract}
Introduction: Food insecurity and foodborne disease are important issues in Canada, and the public health actions taken to address them can be conceptualized as factors shaping the food environment. Given emerging evidence that these two areas may interrelate, the objective of this study was to explore ways in which community food security efforts and food safety practices (and the population health issues they aim to address) may intersect in British Columbia, Canada, and interpret what this might mean for conceptualizing and attaining healthier food environments.
\end{abstract}

Methods: We conducted 14 key informant interviews with practitioners working in community food security and food safety in British Columbia, and used qualitative descriptive analysis to identify examples of intersections between the sectors.

Results: Participants identified four key ways that the two sectors intersect. They identified (1) how their daily practices to promote safe or healthy food could be helped or hindered by the activities of the other sector; (2) that historically disjointed policies that do not consider multiple health outcomes related to food may complicate the interrelationship; (3) that the relationship of these sectors is also affected by the fact that specific types of food products, such as fresh produce, can be considered both risky and beneficial; and (4) that both sectors are working towards the same goal of improved population health, albeit viewing it through slightly different lenses.

Conclusion: Food security and food safety connect in several ways, with implications for characterizing and improving Canadian food environments. Collaboration across separated public health areas related to food is needed when designing new programs or policies aimed at changing the way Canadians eat.

Keywords: food security, food safety, public health practice, policy

\section{Introduction}

Food environments have been defined as "the physical, social, economic, cultural, and political factors that impact the accessibility, availability, and adequacy of food within a community or region." ${ }^{1}$ Under this definition, actions taken by public health practitioners that alter food availability and accessibility can thus be conceptualized as forces influencing food environments. Additionally, the foodhealth outcomes that the field of public health aims to address can be conceptualized as factors that drive public health actions. This study explored two domains of public health action related to foodcommunity food security and food safetyand the population health issues they aim to address (i.e. food insecurity, including access to healthy foods, and foodborne disease). Because these domains have historically been considered separately by public health organizations, policy makers and researchers, this study aimed to explore ways in which they might intersect,

\section{Highlights}

- Efforts to promote food security and healthy eating can counter efforts to ensure safe food, and vice versa, although both have the same goal of improved population health.

- Historically disjointed policies (e.g. food premises regulations that focus on food safety, Canada's Food Guide that focuses on nutrition), and foods that are both risky and beneficial (e.g. produce) create challenges to enacting population health improvements.

- Actions designed to increase fresh food access, or limit foods of high microbial risk, should be developed collaboratively to mitigate unintended consequences.

- Public health activities related to food and health intersect in unexpected ways; collaboration across these separate public health domains is needed when designing programs or policies aimed at changing the way Canadians eat.

both within public health practice and through the lens of their influence on food environments.

Food security activities are those that aim to ensure that "all people, at all times, have physical and economic access to sufficient, safe and nutritious food to meet their dietary needs and food preferences for an active and healthy life." ${ }^{2}$ Included within this definition are efforts aimed at improving community food security such as coupon programs and farm-to-school 
initiatives designed to increase public access to fresh and healthy food. ${ }^{3,4}$ Food safety activities, which aim to reduce the risk of foodborne disease in the population, include actions such as creating legislation prohibiting unsafe foods (such as the Safe Food for Canadians $A c t^{5}$ ), and outbreak investigations and food recalls. ${ }^{6,7}$ Despite the historical separation of such activities in public health practice, there is emerging evidence that food insecurity and foodborne disease share upstream determinants; for example, low income is a risk factor for, and climate change can exacerbate, both food insecurity and foodborne disease in the population. ${ }^{8}$ There is also evidence that public health actions undertaken to address one of these population health issues can inadvertently and negatively impact the other. For example, community food security programs aimed at improving access to healthy foods, such as the Farmer's Market Coupon Program, ${ }^{3}$ increase consumption of fresh produce, which is a leading source of foodborne disease outbreaks. ${ }^{9,10}$ Similarly, the 2004 British Columbia (BC) Meat Inspection Regulation, designed to improve food safety, decreased meat processing capacities in remote communities, ultimately increasing food insecurity. ${ }^{11,12}$

These observations suggest that a key yet underinvestigated component of characterizing the Canadian food environment is to understand the ways in which different public health actions, undertaken in areas related to food and health, may actually be playing out in unexpected ways. Although actions to increase access to fresh and healthy foods (e.g. healthy corner store interventions) are recognized elements shaping food environments, ${ }^{13-16}$ and although formal food safety activities (e.g. licensing, inspection) have recently been noted as policy tools with which to improve food environments, ${ }^{17}$ studies that explicitly explore food safety and foodborne disease risk as part of healthy food environments in Canada are lacking. Given this lack, and given the potential for interrelationships between foodborne disease, food insecurity, food safety, and community food security (hereafter, "food security") activities, the objective of this study was to explore ways in which food security efforts (and the food insecurity issues they aim to address) and food safety practices (and the foodborne diseases they aim to address) may intersect, within the province of British Columbia, Canada, from the perspective of the individual public health practitioner. We then interpreted study findings in the context of the Canadian food environments to suggest areas for future attention.

\section{Methods}

We conducted key informant interviews with purposefully sampled individuals working in public health in $\mathrm{BC}$, who had either a community food security or food safety focus, and who had experience working with practitioners in the other sector. We considered those with a food security focus to include both food security and healthy eating practitioners working in public health agencies or community organizations with an aim to increase the population's access to healthy food. We considered those with a food safety focus to include practitioners working in public health agencies with an aim to reduce foodborne disease in the population. Interviews were conducted as part of a broader study whose ultimate goal was to identify barriers and facilitators to successful intersectoral collaboration between these two areas. A semistructured interview guide, which explored participants' experiences working with the other sector, was developed, piloted and revised based on feedback regarding the clarity of the questions. We obtained ethics approval from a University of Waterloo Research Ethics Committee (ORE\#20375).

Participants were recruited via email, and all provided verbal informed consent at the beginning of their telephone interview. Interviews were conducted from January to February 2015, and were one to two hours in length. Audio of the interviews was recorded and field notes were also taken. Interviews were transcribed, and transcripts were corrected against the audio files according to methodology outlined by Braun and Clarke ${ }^{18}$ and anonymized; quotations appear herein with disfluencies removed to improve readability. Participant recruitment continued until no new themes emerged from the interviews, as per Morse et al. ${ }^{19}$

Of the 19 individuals invited to participate, 14 agreed, one declined and four did not respond within the study timeframe. The 14 participants worked in five of the seven BC health authorities, three provincial-level government organizations and two nongovernmental organizations. They had either front-line or management perspectives in the areas of food security
( $\mathrm{n}=6)$, food safety $(\mathrm{n}=5)$ or both $(n=3)$; and were all in mid to late career. Eight were female and six were male.

To maintain the confidentiality of the results, participants are only identified in this article by position and sector. Food safety practitioners were more easily identified by their position than those working in food security; the majority were environmental health officers, and managers and directors of health protection and environmental health departments. In contrast, food security practitioners held more diverse positions, working in the areas of healthy eating promotion and improving access to local foods, and included community nutritionists and public health dietitians (hereafter called collectively "dietitians”), and project leads.

We conducted qualitative descriptive analysis to identify and explore examples of intersections between the two sectors as discussed by the participants. ${ }^{20}$ Analysis was managed in ATLAS.ti version 1.0.50 (282) (ATLAS.ti Scientific Software Development $\mathrm{GmbH}$, Berlin, GER). We inductively analyzed the data as per Braun and Clarke. ${ }^{18}$ After immersion in the data, examples of intersections were coded and used to develop preliminary themes. We reviewed and revised themes iteratively, and then further explored each theme using the specific settings and instances described by participants. We used memos throughout the coding process to revisit questions and reflections regarding the data, as per Birks et al. ${ }^{21}$

\section{Results}

Through their discussions, participants revealed four important ways in which food security and food safety intersect within the BC public health context. They described (1) how their daily practices to promote safe or healthy food could be helped or hindered by the activities of the other sector; (2) that historically disjointed policies that do not consider multiple health outcomes related to food may complicate the interrelationship; (3) that the relationship of these sectors is also affected by the fact that specific types of food products, such as fresh produce, can be considered both risky and beneficial; and (4) that both sectors are working towards the same goal of improved population health, albeit viewing it through slightly different lenses. 


\section{The intersection of specific public health practices}

Participants described many ways their own public health activities influenced, or were influenced by, the public health efforts of the other sector (Table 1), including how this intersection posed a barrier to achieving their particular public health goals. For example, food security practitioners experienced a conflict when providing traditional, Indigenous food in facilities licensed to provide or serve food to the public (e.g. daycares, hospitals, dining facilities). As Participant (P) 11 (a dietitian) explained, being able to serve traditional food in public venues is important for food security:

[F]or First Nations, food security is so much bigger than just having enough food. It's having culturally acceptable food. It's being able to access and have rights to the lands and waters to source those foods, so, being able to serve them at a conference facility, it's health promoting in a much bigger picture, social determinants of health.

However, efforts to provide traditional foods within licensed facilities were often seen as being impeded by food safety activities, as illustrated by P4 (dietitian), who described how the Hazard Analysis Critical Control Points (HACCP) approach to food safety, which aims to ensure the microbial safety of foods by implementing control procedures at important steps during food production, comes into play:

Well, there is a big issue that arises whenever you're speaking of aboriginal care facilities, whether they're for children, or for seniors, or for people who might be living with disabilities or whatever, and that is that...provision of traditional food is very challenging in those settings, because the settings want to assure safety, and so want to assure that foods have travelled along a HACCP protected path.... But traditional foods don't travel along a HACCP protected path.... So it becomes very challenging, because if you're an aboriginal senior, and all your life you've eaten home canned fish, or fresh caught fish, and you enter a care facility and you want fish, and you get [brand name] frozen fish sticks.... And yet there are no facilities that have that HACCP protected path, so you can say that this has been safe all the way along its journey, from source to plate.

Food safety practitioners experienced a similar conflict in the course of pursing their daily activities in local farmers' markets, a venue in which food security advocates worked to increase access to local, fresh food. As P3 (environmental health officer) explained, when food security efforts went ahead without considering foodborne disease risks, environmental health officers-who have a legal enforcement role to ensure food sold to the public is safe-were then put in a position where they had to react:

[The population health group] were putting together a list of local food providers.... And what happened is they were charging out there and getting everybody signed up, and getting names and numbers where you can buy, "whatever," and the problem was, "whatever" is what was on the list including uninspected meat.... Once the meat inspection regulations came in, and somebody was cooking perogies for sale, and somebody else was making goat cheese out of uninspected milk, and so, some fairly serious public health issues ... in my mind, and there was no channel for communication, there was just great ideas and they go out and do them, and without any collaboration or even inquiry with us, so when we get wind of it, it's like, "no, you're done, you can't do that." And, of course, the war's on [laughing].

\section{The impact of policies that only consider one food-health outcome}

When discussing conflict between food security and food safety efforts, participants spoke about how this was, in part, a product of disjointed policies and regulations that historically have not considered other food-health outcomes in their development and implementation. For example, P12 (dietitian) explained how guidelines, like the food safety guidelines followed within BC's FOODSAFE food handler training program, ${ }^{22}$ can cause issues for preschools who serve food to children:

We've always had an interest, our program, the community nutrition program, in doing more work with the preschool population, and encourage, and promote healthy eating in those areas, those facilities, and what we were finding is that the [food safety] regulations were almost working against us.... On one hand there was licensees, the child care providers were hearing a strong, "you need to be FOODSAFE" message, to the point where, I believe that if it was in a crinkly package, that was good to serve almost, because it was FOODSAFE, and then nutrition was coming along with, "well, we want healthy foods, which are fresh foods," and I think they were somewhat bound with what they could do.

P12 went on to explain that existing food safety regulations often do not consider the impact the regulations could have on healthy eating:

[E]nvironmental health officers, they're bound by the Food Premises Regulation.... And the actions of the environmental health officers and the licensing officers, as well, and our own documents, weren't as supportive as they could be for healthy eating.... Our food safety requirements for child care providers, for licensed child care facilities, were very strongly orientated to food safety, without the consideration of healthy.

In some instances, the policy disconnect was implicit in participants' statements, for example, in how P13 (food security lead) described Canada's Food Guide as the ultimate guideline in the province, while dismissing the risk of $E$. coli infection (that causes about 33000 illnesses in Canada each year $^{23}$ ) and the food safety regulations designed to minimize such risk:

Basically, Canada's Food Guide is a national guideline.... For healthy eating in Canada, and provincially we use that as a tool, and everybody is implementing working towards healthier food choices.... So, you can't trump that. You can't say, "Kids can't eat salads, because they're dangerous." ... You can't ban hamburger from preschools, right, [laughing] 
TABLE 1

Example situations experienced by B.C. public health practitioner participants, in which food security and food safety intersected

Situation

Providing local, fresh, and

healthy food in schools

Providing healthy food in

child care centres

Providing local food in hospitals

Providing local food at farmers markets

Promoting community gardens

upporting access to local food and agriculture

Establishing food safety through local meat regulations

Food donations to food banks and through community kitchens

Supporting use of culled game meat

Supporting access to local, healthy food donations through gleaning projects

Improving the health of new mothers and young children
Example quotation

So, with the Environmental Health Officers' perspective, it's very much about-well, their role is food safety—so often the foods that are safe- safer-are often packaged foods, and processed foods, which don't always align with some of the foods that we're trying to promote with schools. [P10, dietitian]

You can get this list of low risk foods ... highly packaged, right, highly processed, highly packaged, very unhealthy. But they are low risk, so-you can really bump up against, say if you're working with a preschool, daycare setting, and you want them to have healthy foods for kids, but you're coming in with the wrong guidelines when you just say, "You can't have those foods." ... You've got to say, "You've got to show us how you cook foods properly." [P13, food security lead]

There's the discussion about local food provision in hospital kitchens because it's a big buyer of food, and the discussion, "Well, maybe we can get the local meat supplier to supply the meats for the products that they're serving in the hospital, that would be a great market for them to get into," and then you start to think about, "Well, do they really have the infrastructure to be able to support that on a consistent basis, and can they do it safely?" ... I think that that's one of the arguments against local provision of food, is that the hospitals need a large volume of very uniform food that doesn't need a lot of processing ... safety is another thing, do they have the mechanisms in place, you think a produce supplier, do they have the on-farm food safety aspects, are they following the GAP [Good Agricultural Processes] processes, and do they have that infrastructure in place to be able to produce the reassurance I guess, or the quality of the food, and reassure the users of that that it's of sufficiently high quality that they don't have to worry about a food safety risk when they accept it at the back door of the hospital. [P6, manager, health protection/ environmental health]

We weren't happy with hazardous foods at the farmers' market and we wanted some labelling happening on canned goods, and this kind of thing that wasn't part of what [the food security/population health group] were doing. They were just pushing to get some local food out. [P3, environmental health officer]

I mean I would use community gardens right now, they're doing the study out of UBC. You've probably read it, around soil contamination and lead, high lead levels in some Vancouver community garden areas. So, of course that's a huge concern. We don't want people to get lead poisoning, but if we don't have that conversation from the food security perspective, maybe it just gets all shut down and there's no more community gardens in the City of Vancouver, well, that's not good. [P7, manager, food security]

... but people just, I guess what it was, "Well, if it was just grown across the street, and it's just a little one-acre farm, then it has to be good for us," attitude, and from the agriculture side, it does sound wonderful, and it could be just awesome, but it could be not, and we just couldn't take that risk, feeding somebody else's children. [P9, food security project lead]

There was a recognition that in some of our more rural remote locations, it wasn't feasible to actually create a provincially licensed abattoir, so they introduced an on-farm slaughter licence, and we have Class D and E licences available in those rural remote locations, and we also have Class E licences that are available outside of those locations, with the feasibility study, and the reason being because if you can take your animal to an abattoir, we would prefer it, because of the food safety standards that are in the abattoir.... So that was kind of a response, recognizing that we wanted to continue to support local food, but yet we wanted to have standards in place. Because we do, obviously, want to ensure that all British Columbians have access for safe local meat, right. [P8, manager, health protection/environmental health]

[...] we consider produce quite often now as one of the riskier foods [...] just based on the number of outbreaks that have occurred in the last decade or so, often produce is going to be implicated in outbreaks, and certainly this is one of the food types that you'd want to see in a soup kitchen or food bank - or available for donation, healthier food products obviously than the Kraft Dinner [...] model, so I think that we have to take that into consideration, that there are some handling precautions that need to be taken, and there are some limitations on what can be done safely and what can't be done, so, those have to be considered as well. [P6, manager, health protection/environmental health]

Say with the culled game meat, I mean we were getting requests from these municipalities or regional districts saying, "Hey, we're having all these deers killed, and wouldn't it be nice if we could somehow process and donate the food to the local food bank, or First Nations folks or whoever," and we're like, "Well, yeah, that would be a good idea because it's high quality food, so let's kind of work together and make sure that it's done safely. So that they don't get sick when they eat the food." [P1, food safety expert]

Community nutrition programs have gleaning projects in the [region name], there's a lot of tree fruits there that are left over at the end of the year, so we've worked with them on providing some food safety tips along the gleaning project side of things. [P6, manager, health protection/environmental health]

There's a lot of clinics being held in public health these days, related to breast feeding in new mothers, and there's-we're bringing in other groups in there to talk about food safety with them, to disinfection, to talk about personal hygiene in the home, and especially with a lot of pets, and toys and any of the infections that can occur in the home, how to avoid them, and so it brought infection control in there, it brought the food safety people in there, it brought the food security people in there, it brought the healthy eating people in there, so there's a wide variety. [P5, environmental health officer] 
because they have a risk of $E$. coli ... whatever.

Beyond the regulations and guidelines themselves, some participants discussed how different interpretations of food safety regulations can negatively impact food security and healthy eating, as illustrated by P6 (manager, health protection/ environmental health):

And I think that for a lot of people, yeah, the light bulb comes on, "Oh yeah, this makes sense, it's not really that big a deal, let them just go at it," and then there's other people saying, "Well, no, it doesn't meet the letter of the law," so, for some staff, it really depends on their own personal perspective as to how they read the legislation and how much they feel they have that discretion to work around the letter of the law, to do what probably is the right thing to do.

Participants also described how reinterpreting existing regulations can help mutually support both food safety and food security goals. For example, P12 (dietitian) pointed out that the 2007 Child Care Licensing Regulation ${ }^{24}$ actually supports both food security and food safety in child care centres:

Where I think we got some buy in, as well, through the health protection-was that doing those food activities with children would actually meet some of the Child Care Licensing Regulation statements or requirements. Because we looked at the Child Care Licensing Regulation, it states-where is it? - "a licensee must establish a program to instruct and practice the rules of health and hygiene." That's actually Section 46 ... [laughing] ... of the Child Care Licensing Regulation. So, we argued that providing food exploration and preparation experiences are ideal hands-on opportunities to teach children about hygiene, health, food safety and hand washing. So, that was one argument, and then, also, there's a whole Section 48, Nutrition and Child Care Licensing Regulation, that states that a child- "that a licensee must ensure that each child has healthy food and drink according to Canada Food Guide," and a whole bunch of stuff, right, and then we argued that best practice is to expose children to a variety of healthy foods and food experiences, that are fresh and minimally processed, and that child care providers, that they were confined to prepackaged foods to avoid the approval process. They were going to be compromising nutritional quality. Nutritional quality was a big piece of the Child Care Licensing Regulation, so, yeah, for those two reasons, in the Child Care Licensing Regulation, we kind of flipped it around and said, "These changes actually help you meet regulations."

P6 (manager, health protection/environmental health) also spoke to reinterpretation, when discussing guidelines that had been developed to interpret food safety legislation in a way that also supports specific food security and healthy eating initiatives:

And I think that, really what I see in a lot of these food security initiatives is that the staff kind of need the permission to go ahead and consider these things, so there's a couple things that come to mind, is that, yeah, they want to know that they're not going to get in trouble for approving something that they maybe shouldn't have approved if they were following the letter of the law, but also that there's some consistency in that if you're giving somebody an opportunity to do something like this, you may be perceived as being a bit soft in the legislation, but if there's a guideline to support it, or if there's some other documentation that says, if some precedent was set, "Yeah, you can allow this and this and this in this type of facility," then that, kind of, gives them that permission to go ahead and allow that softening of that hard interpretation of the legislation.

\section{The impact of the food product: what's healthy isn't always safe, and what's safe isn't always healthy}

Much of the conflict that participants described at the practical and policy levels was related to the fact that the risk of foodborne disease can be higher with the types of fresh and healthy foods that food security efforts aim to promote, and that foods with a low food safety risk are often prepackaged and processed, and thus less healthy and nutritious. Participants predominantly talked about fresh fruits and vegetables versus prepackaged and processed foods or foods that are "in a crinkly package” (P12, dietitian). For example, P6 (manager, health protection/environmental health) compared produce to Kraft Dinner when discussing food donations to places such as food banks, describing the risks of these two types of foods:

We consider produce quite often now as one of the riskier foods ... just based on the number of outbreaks that have occurred in the last decade or so, often produce is going to be implicated in outbreaks, and certainly this is one of the food types that you'd want to see in a soup kitchen or food bank-or available for donation, healthier food products obviously than the Kraft Dinner ... model, so I think that we have to take that into consideration, that there are some handling precautions that need to be taken, and there are some limitations on what can be done safely and what can't be done, so, those have to be considered as well.

Likewise, P10 (dietitian) illustrated that foods that minimize foodborne disease risk are often not considered healthy:

[L]ooking at this one document that used to be in place-well, I think it might still be, because this initiative isn't finalized yet-of this list of, "These are the safe foods that you can do in school." I think we actually might still have a Health Link BC document on FOODSAFE that says "Oh, baked goods, high in sugar, or something like that, are safer than doing something like vegetables."

While the idea of fresh produce versus prepackaged foods predominated, other specific types of foods were mentioned in the context of the intersection between food safety and food security. For example, P6 (manager, health protection/environmental health) described how foods that are potentially hazardous from a food safety perspective, such as meat, dairy 
and eggs, are also some of the more nutritious foods:

Unfortunately, the legislation really doesn't speak to any one specific type of food, it talks about potentially hazardous foods a little bit, so that has historically been a bit of a cutoff, and unfortunately, a lot of potentially hazardous foods are also some of the more nutritious foods as well, so ... you've got dairy products, and when you've got some meat products, and eggs, and things like that, there's a higher level of risk generally associated with them, but that's if there's improper handling along the way.

Similarly, P11 (dietitian) discussed how foods that are beneficial from a food security perspective, such as community-prepared traditional foods, may be risky from a foodborne disease perspective:

[F]rom a First Nations perspective... our environment really has changed, and there's a lot more potential for foodborne illness than there ever was before, and our methods are changing a bit as well, which increases that potential for foodborne illness, when you think of fish or wild game, some people like towell fish in particular, people have taken to canning, or jarring fish.... And, it's super common in First Nations communities to do that with the boiling water bath, which is not the food safe standard for processing. The standard is pressure canning, and the reason is the temperature that you can bring it to ... you want it to kill potential spores, right, the risk is actually death.

In addition to the above examples, one participant (P13, food security lead) did describe a situation in which the food security and food safety goals of reducing health risks aligned within a food product, when discussing the issue of expired infant formulas:

... with infant formulas and baby foods, the "best before dates" and I was quite concerned about the rancidity ... in the formulas, and, of course, that can be a food safety discussion, but it's also a very important nutrition discussion, right ... because of the long-chain essential fatty acids, if they're going rancid you're really causing a problem.... That's also a really important nutrition issue. So, rancidity is not just a toxicity piece it's a nutrition component.

\section{The recognition that, for both sectors, "the} ultimate goal is the best health possible"

Overall, participants spoke to the importance of thinking broadly about food's link with population health. For example, P6 (manager, health protection/environmental health) explained that when working toward improved health for the population, it is important to look beyond your own sector to recognize the role of other food-health outcomes:

But I think there is some understanding that there's more to food than just the food safety side of things, there's a lot more to it in terms of the public health benefits, and I think if you look at the determinants of health, and anybody that's done any work in that area clearly sees that food safety is one portion of it, but there's many other portions, and many other aspects of food that will influence a beneficial public health outcome, so, whether it's nutrition, whether it's food security, there's other things that happen with food that we have to be cognizant of.

In addition, as P4 (dietitian) noted, food plays a bigger role in health than just the physical act of food consumption: "And the local people that I work with, that we all work together, and they've heard me expound on [laughing] those types of issues, that food isn't just food, it's culture, and [laughing] it goes beyond satiety."

Despite describing how activities and policies in food security and food safety can be at odds, most participants recognized that both sectors play an important role in improving population health. For example, P1 (food safety expert) noted that both sectors value food safety's health outcome, stating: "In most cases, they want to see the same things that you want to see in terms of, just safe food, I mean, no one wants to go out, and make anybody sick." Likewise, P10 (dietitian) pointed out that one of the goals of food security is to instill long-term healthy habits in the population, and that food safety is often incorporated into this goal: "Well, both in terms of child care and school settings, it's when children are learning eating habits that will hopefully serve as a foundation throughout their life. So we want both healthy and safe food, in those cases." In addition, participants recognized that food safety is often considered an important component of food security, as illustrated by P1 (food safety expert): "The whole idea of food security, you know, good, nutritious food for everybody, or access to it, but good nutritious, safe food ... to me, really it's definitely connected to our very central theme, just as important as the nutrition."

Finally, participants expressed the idea that the ultimate goal of both the food security and food safety sectors is to improve the health of the population, as described by P12 (dietitian) when discussing food in childcare settings:

The take home message that we're trying to make is like the ultimate goal is the best health possible for children in care. It includes immediate health and safety, as well as lifelong health, and keeping in mind about how the effect of chronic disease, and the percent of population that's going to be affected by chronic disease, due to poor eating habits and lifestyle, versus the immediate food safety risk.... And in trying to balance them, because they're both really important.

\section{Discussion}

This study investigated ways in which community food security ("food security") and food safety intersect, in the context of public health practice in BC. Participants revealed ways in which their daily practices, aimed at improving either the population's access to healthy food, or the safety of food consumed by the public, could be helped or hindered by the activities of the other sector, in part due to historically disjointed policies that do not consider multiple health outcomes related to food. Participants also identified how specific types of food products, such as fresh produce, can be both risky and beneficial to the population's health. Despite these tensions, participants recognized that both sectors are working towards the same overall goal of improved population 
health, albeit using slightly different lenses, an attitude that allowed participants to collaborate with the other sector despite the difficulties they faced. These findings suggest several considerations for future characterizations of, and actions aimed to improve, food environments in Canada.

First, these findings suggest that, when acting to create healthier food environments, engaging public health practitioners must go beyond involving those with mandates for nutrition, healthy eating and food security to also include those with a mandate for food safety. Although considering food safety when measuring or acting to improve food environments has been previously suggested, ${ }^{17,25}$ this study demonstrates how collaboration with food safety practitioners, or the lack thereof, can impact population health efforts aimed at improving community nutrition environments. In this study, participants provided many examples of how the lack of engagement across food-related mandates made it more difficult for them to work toward safe and healthy diets within given communities. Previous work by Martin and Perkins uncovered existing tensions between food safety and food security practitioners from multiple Canadian provinces, ${ }^{26}$ suggesting that the findings presented here may be applicable beyond the British Columbia context. Further work to determine how best to support collaborations between practitioners in these areas is warranted.

Beyond the actions of individual public health practitioners, these findings also suggest that provincial and federal policies related to food and health should consider potential impacts and influences on health, beyond their target outcome. This concept has been previously suggested, ${ }^{8}$ and this study provides evidence that policy disconnects can result in less effective actions by frontline practitioners, who must navigate and negotiate areas of conflict in the policy and legislative environment when delivering programs. Formal guidelines may facilitate such navigation, particularly when developed collaboratively. For example, BC's 1997 Food Donor Encouragement Act (which absolves food donors acting in good faith of liability for negative health consequences from donated food), ${ }^{27}$ can act at cross-purposes to conventional food safety standards, creating situations in which public health practitioners may have conflicting goals (e.g. increasing donations of fresh foods versus enforcing food safety standards), particularly around specific foods such as fresh produce and processed foods, as noted by our participants. In 2016, BC set out guidelines, co-developed with food safety and food bank representatives, that better support safe food practices within the realities of organizations that rely on food donations to operate, including their goal of offering nutritious foods to individuals in need, and the elevated vulnerability of specific client subpopulations (e.g. the elderly, children, immunocompromised individuals) to foodborne pathogens. ${ }^{28}$

In this study, participants were able to discuss the legislation, regulations and policies associated with food safety much more clearly than those associated with food security, in part because food safety legislation has long existed in Canada (e.g, Canada's 1920 Food and Drugs Act ${ }^{29}$ ), compared to relatively new food securityrelated legislation (e.g. BC's Food Donor Encouragement Act, 1997;27 and Bill M 222, currently proposing a BC Local Food Act $\left.^{30}\right)$. That food safety legislation is more established and recognized than food security legislation has the potential to exacerbate conflict between food safety and food security practitioners, for whom legislation can prescribe public health activities. In our study, participants described positive and negative impacts of the BC Food Safety $A c t^{31}$ within their daily practices (mainly pertaining to the enforcement of food safety standards), but other legislation was not as explicitly nor widely noted. In BC, food safety and food security are two of the province's 21 core public health programs, and there is increasing recognition of their interdependence, ${ }^{32}$ with access to safe foods noted as an important part of food security. The food safety core program is focussed on reducing harm related to possible microbial and chemical contaminants, and is underpinned by two provincial acts: the Food Safety Act $^{31}$ and the Public Health Act. ${ }^{33,34}$ The food security core program, which is focussed on creating a foundation for healthy eating and a stable and sustainable food supply, ${ }^{35}$ is also underpinned by the Food Safety Act and the Public Health Act, ${ }^{36}$ as well as the Food Donor Encouragement Act. ${ }^{27,36}$ The common legislative underpinnings of these core programs suggest that it may not be the legislation itself, but rather its interpretation and application (including via existing policies and established practices that often only consider one food-health outcome), that may lead to tensions in public health practice. Indeed, in this study some participants described how reinterpreting existing regulations can help mutually support both food safety and food security goals. Exploring how existing legislation may be reinterpreted thus is warranted, but is beyond the scope of this paper.

In our study, participants spoke about particular foods that have both health risks and benefits; the predominant examples were processed, packaged foods and fresh produce. Given that produce is an important cause of foodborne illness in Canada, ${ }^{10}$ food environment interventions that aim to increase access and availability of produce should proactively work to mitigate the potential for exposure to pathogens. To date, the dynamic microbial ecosystem of food has not been explicitly considered as a facet of healthy food environments, and future integration is needed. To this end, these findings illustrate that, when characterizing food environments, food safety factors should be measured. To date, the studies of Canadian food environments that have considered diet quality and safety have focussed on aspects such as perceived freshness ${ }^{37}$ and physical safety related to travelling to food establishments, ${ }^{38}$ and have noted issues related to mice soiling foods. ${ }^{39}$ Despite evidence from the US that foods, particularly produce, from markets and retail establishments in low-socioeconomic areas can have higher levels of microbial contamination versus those from high-socioeconomic areas, ${ }^{40-42}$ such established food safety indicators have not been included in Canadian food environment assessments. One reason noted for this omission is a lack of data; ${ }^{25}$ however, given the wealth of ongoing inspection data collected by local and provincial public health organizations (e.g. Vancouver Coastal Health, ${ }^{43}$ Region of Waterloo ${ }^{44}$ ) incorporating food safety measures into food environment characterizations is theoretically feasible and should be actively explored.

Other previous research examining the link between food safety and food security has focussed on assessing the inclusion of food safety within food security initiatives, ${ }^{45}$ and the impacts of a particular food safety regulation on population food security, ${ }^{11,12}$ as well as exploring risk factors that can be common to both food insecurity and foodborne disease (e.g. 
socioeconomic status, ${ }^{46}$ climate change ${ }^{47}$ ). This study furthers past work by identifying multiple scales at which food safety and food security intersect (i.e. food products, public health practices, government policies). It also highlights issues at play across the Canadian food system, namely the historical separation of food safety and food security that has occurred in public health practice, and the relatively greater level of institutionalization of the food safety function of public health versus the food security function. In our sample, food safety practitioners had more clearly defined positions, including the certified position of Environmental Health Officer, ${ }^{48}$ whereas food security practitioners' roles were more diverse and often included community nutritionists and public health dietitians. Food safety practitioners were found solely in government and health authority organizations, whereas food security practitioners were also found in community and nongovernmental organizations. This may be important when considering future community-engaged food initiatives, because community organizations may not represent nor advocate for addressing the actual foodborne risks faced by Canadians. For example, at the time of writing, BC had numerous community-based food security networks, with 14 in the Vancouver area alone, ${ }^{49}$ but no community-based groups advocating for food safety. Thus, public health activities, such as local food policy development, that bring community voices to the discussion may not fully address food safety issues within planned activities. If this then leads to future food safety risks, to which food safety practitioners must respond in ways that are seen as negative (e.g. closing premises, recalling foods), a potential cycle of disengagement and distrust may occur, as noted by food safety participants in this study. Engaging across sectors early in the development of public health actions may be an important way to decrease such division.

\section{Strengths and limitations}

There is a paucity of literature on this topic, and thus key informant interviews allowed for an in-depth exploration of the various ways that the food security and food safety sectors might intersect, as experienced by public health practitioners in $\mathrm{BC}$, revealing several important areas for consideration when characterizing or acting to change food environments. Our work can guide future, more comprehensive assessments of a wider range of practitioners and provinces. The main limitation of this study is that we targeted individuals who had experience working with the other sector; it is possible that their experiences are different from those of others who have either not worked with the other sector, or who have tried but not succeeded. As well, our participants worked in public health, such that the tensions and intersections reported here may not represent those experienced by others working outside the public health domain. Interviews with others involved in improving food safety and food security (e.g. food skills educators, soup kitchen operators) are needed to further uncover tensions and considerations at the intersection of these two areas beyond the realm of public health. Nevertheless, this study uncovered important areas for consideration when conceptualizing how public health activities and policies can act to shape Canadian food environments.

\section{Conclusion}

This study highlights how food security and food safety, two important but historically separate public health sectors in Canada, are actually connected in several ways. It also broadly demonstrates that both foodborne disease and food safety activities are important factors impacting healthy Canadian food environments. It behooves practitioners in these areas to work more collaboratively, in particular to mitigate any unintended population health consequences of activities designed to increase access and availability of fresh foods, including produce, or to limit exposure to foods of high microbial risk. Even beyond food security and food safety, these findings suggest the need to consider how various public health actions related to food and health may intersect in unexpected ways to shape the current food environment, highlighting the importance of engaging across units, both within and between public health organizations, when designing new programs or policies aimed at changing the way Canadians eat.

\section{Acknowledgements}

The key informant interviews were funded by a contract from the British Columbia Centre for Disease Control (BCCDC), and the authors thank Karen Rideout and Melanie Kurrein (BCCDC) for their support of that work. The views in this paper represent those of the authors, and not the views of the BCCDC. The authors also thank Abra Brynne (BC Food Systems Network) for discussing, and providing input into, the concepts in this paper.

\section{Conflicts of interest}

All authors declare no conflicts of interest or competing interests.

\section{Authors' contributions}

SM designed the study, KS analyzed the data with involvement of all authors, all authors interpreted the data, KS and SM drafted the paper, and all authors revised and finalized the paper.

\section{References}

1. Rideout K, Mah CL, Minaker L. Food environments: an introduction for public health practice [Internet]. Vancouver (BC): National Collaborating Centre for Environmental Health; 2015 Dec [cited 2016 Oct 25]. Available from: http://www.ncceh.ca/sites /default/files/Food_Environments_ Public_Health_Practice_Dec_2015.pdf

2. Food and Agriculture Organization (FAO) of the United Nations. Rome Declaration on World Food Security and World Food Summit Plan of Action [Internet]. Rome (IT): FAO; 1996 [cited 2016 Apr 4]. Available from: http://www.fao.org/docrep/003 /w3613e/w3613e00.HTM

3. BC Association of Farmers' Markets. Farmers' market coupon program [Internet]. Vancouver (BC): BC Association of Farmers' Markets; 2014 [cited 2016 Apr 4]. Available from: http:// www.bcfarmersmarket.org/nutrition -coupon-program

4. Government of British Columbia. Food security [Internet]. Vancouver (BC): Government of British Columbia; 2017 [cited 2017 Apr 12]. Available from: http://www2.gov.bc.ca/gov /content/health/keeping-bc-healthy -safe/food-safety/food-safety-sanitation -plans/food-security

5. Safe Food for Canadians Act, S.C. 2012, c. 24 [Internet]. Ottawa (ON): Minister of Justice; [modified 2014 Jun 19; cited 2016 Apr 4]. Available from: http://laws-lois.justice.gc.ca/ PDF/S-1.1.pdf 
6. McIntyre L, Wilcott L, Naus M. Listeriosis outbreaks in British Columbia, Canada, caused by soft ripened cheese contaminated from environmental sources. BioMed Res Int [Internet]. 2015 [cited 2016 Sep 29];131623. doi: 10.1155/2015/131623.

7. MacDonald DM, Fyfe M, Paccagnella A, Trinidad A, Louie K, Patrick D. Escherichia coli 0157:H7 outbreak linked to salami, British Columbia, Canada, 1999. Epidemiol Infect. 2004; 132:283-9. doi: 10.1017/S0950268803 001651 .

8. Majowicz SE, Meyer SB, Kirkpatrick SI, et al. Food, health, and complexity: towards a conceptual understanding to guide collaborative public health action. BMC Public Health [Internet]. 2016 [cited 2016 Sep 15]; 16:487. doi: 10.1186/s12889-016-3142-6.

9. Painter JA, Hoekstra RM, Ayers T, et al. Attribution of foodborne illnesses, hospitalizations, and deaths to food commodities by using outbreak data, United States, 1998-2008. Emerg Infect Dis. 2013;19(3):407-15. doi: 10.3201/eid1903.111866.

10. Kozak GK, MacDonald D, Landry L, Farber JM. Foodborne outbreaks in Canada linked to produce: 2001 through 2009. J Food Prot. 2013; 76(1):173-83. doi: 10.4315/0362-028X .JFP-12-126.

11. Miewald C, Hodgson S, Ostry A. Tracing the unintended consequences of food safety regulations for community food security and sustainability: small-scale meat processing in British Columbia. Local Environ. 2015;20(2): 237-55. doi: 10.1080/13549839.2013 .840567 .

12. Miewald C, Ostry A, Hodgson S. Food safety at the small scale: the case of meat inspection regulations in British Columbia's rural and remote communities. J Rural Studies. 2013;32:93-102. doi: 10.1016/j.jrurstud.2013.04.010.

13. Minaker LM, Shuh A, Olstad DL, Engler-Stringer R, Black JL, Mah CL. Retail food environments research in Canada: a scoping review. Can J Public Health. 2016;107(Suppl. 1): eS4-eS13. doi: 10.17269/CJPH.107.5344.
14. Glanz K, Sallis JF, Saelens BE, Frank LD. Healthy nutrition environments: concepts and measures. Am J Health Promot. 2005;19(5):330-3.

15. Vine MM, Elliott SJ. Examining local-level factors shaping school nutrition policy implementation in Ontario, Canada. Public Health Nutr. 2014;17(6):1290-8. doi: 10.1017/ S1368980013002516.

16. Cavanaugh E, Green S, Mallya G, Tierney A, Brensinger C, Glanz K. Changes in food and beverage environments after an urban corner store intervention. Prev Med. 2014;65:7-12. doi: 10.1016/j.ypmed.2014.04.009.

17. Mah CL, Cook B, Rideout K, Minaker LM. Policy options for healthier retail food environments in city-regions. Can J Public Health. 2016;107(Suppl. 1):eS64-eS67. doi: 10.17269/cjph.107 .5343 .

18. Braun V, Clarke V. Using thematic analysis in psychology. Qual Res Psychol. 2006;3(2):77-101. doi: 10.1191 /1478088706qp063oa.

19. Morse JM, Barrett M, Mayan M, Olson K, Spiers J. Verification strategies for establishing reliability and validity in qualitative research. Int $\mathrm{J}$ Qual Methods. 2002;1(2):13-22.

20. Sandelowski M. Focus on research methods: whatever happened to qualitative description? Res Nurs Health. 2000;23(4):334-40.

21. Birks M, Chapman Y, Francis K. Memoing in qualitative research. J Res Nurs. 2008;13(1):68-75. doi: 10.1177 /1744987107081254.

22. Province of British Columbia. FOODSAFE [Internet]. Vancouver (BC): Province of British Columbia; 2009 [cited 2016 Oct 20]. Available from: http://www foodsafe.ca

23. Thomas MK, Murray R, Flockhart L, et al. Estimates of the burden of foodborne illness in Canada for 30 specified pathogens and unspecified agents, circa 2006. Foodborne Pathog Dis. 2013;10(7):639-48. doi: 10.1089 /fpd.2012.1389.

24. Community Care and Assisted Living Act: Child Care Licensing Regulation, Reg. 332; 2007 [modified 2016 Sep 1; cited 2016 Oct 19]. Available from: http://www.bclaws.ca/civix/document /id/complete/statreg/332_2007
25. Health Canada. Measuring the food environment in Canada. Ottawa (ON): Minister of Health; 2013. [Catalogue No.: H164-155/2012E-PDF]. $88 \mathrm{p}$.

26. Martin W, Perkin K. Food safety and food security: mapping relationships. $\mathrm{J}$ Agric Food Syst Community Dev. 2016;6(2):13-24. doi: 10.5304/jafscd .2016 .062 .001 .

27. Food Donor Encouragement Act (SBC 1997) - Chapter 8 [Internet]. Victoria (BC): Queen's Printer; 1997 [cited 2017 Mar 31]. Available from: http:// www.bclaws.ca/Recon/document/ID /freeside/00_97008_01

28. BC Centre for Disease Control, Greater Vancouver Food Bank, Food Banks BC. Guidelines for food distribution organizations with grocery or meal programs [Internet]. Vancouver (BC): BC Centre for Disease Control, Environmental Health Services; 2016 Feb [cited 2017 Apr 13]. Available from: www.bccdc.ca/health-info/food -your-health/healthy-food-access -food-security

29. Food and Drugs Act, RSC 1985, c. F-27 [Internet]. Ottawa (ON): Minister of Justice; 2016 [updated 2016 Dec 12; cited 2016 Apr 4]. Available from: http://laws-lois.justice.gc.ca/PDF/F -27.pdf

30. Bill M 222-2015 British Columbia Local Food Act, 2015 [Internet]. Victoria (BC): Queen's Printer; 2015 [cited 2016 Oct 20]. Available from: http://www.bclaws.ca/civix/document /id/lc/billsprevious/4th40th:m222-1

31. Food Safety Act (SBC 2002) - Chapter 28 [Internet]. Victoria (BC): Queen's Printer; 2002 [cited 2017 Jun 16]. Available from: http://www.bclaws. ca/EPLibraries/bclaws_new/document /ID/freeside/00_02028_01

32. Provincial Health Services Authority. 2008-09 Annual progress update: core public health programs [Internet]. 2009 [cited 2016 Oct 27]. Available from: http://www.phsa.ca/Documents /200809corepublichealthprograms progressupdate.pdf

33. Public Health Act (SBC 2008) Chapter 28. Victoria (BC): Queen's Printer; 2008 [cited 2017 Jun 16]. Available from: http://www.bclaws .ca/civix/document/id/complete /statreg/08028_01 
34. Government of British Columbia. Food safety legislation [Internet]. n.d. [cited 2017 Jun 16]. Available from: http://www2.gov.bc.ca/gov/content /health/keeping-bc-healthy-safe/food -safety/food-safety-legislation

35. Government of British Columbia. Food security [Internet]. Victoria (BC): Government of British Columbia; [date unknown; cited 2017 Jun 16]. Available from: http://www2.gov.bc .ca/gov/content/health/keeping-bc -healthy-safe/food-safety/food -safety-sanitation-plans/food-security

36. BC Ministry of Health. Model core program paper: food security [Internet]. Victoria (BC): BC Ministry of Health; 2006 [updated 2014 Mar; cited 2017 Jun 16]. Available from: http://www2.gov.bc.ca/assets/gov /health/about-bc-s-health-care -system/public-health/healthy-living -and-healthy-communities/food_ security_model_core_program_paper. pdf

37. Lebel A, Noreau D, Tremblay L, et al. Identifying rural food deserts: methodological considerations for food environment interventions. Can J PublicHealth.2016;107(Suppl.1):eS21eS26. doi: 10.17269/CJPH.107.5353.

38. Le H, Engler-Stringer R, Muhajarine $\mathrm{N}$. Walkable home neighbourhood food environment and children's overweight and obesity: proximity, density or price? Can J Public Health. 2016;107 (Suppl. 1):eS42-eS47. doi: 10.17269/CJPH.107.5347.

39. DyckFehderau D, Holt NL, Ball GD, Alexander First Nation Community, Willows ND. Feasibility study of asset mapping with children: identifying how the community environment shapes activity and food choices in Alexander First Nation. Rural Remote Health. 2013;13(2):2289.

40. Koro ME, Anandan S, Quinlan JJ. Microbial quality of food available to populations of differing socioeconomic status. Am J Prev Med. 2010; 38(5):478-81.

41. Signs RJ, Darcey VL, Carney TA, Evans AA, Quinlan JJ. Retail food safety risks for populations of different races, ethnicities, and income levels. J Food Prot. 2011;74(10): 1717-23. doi: 10.4315/0362-028X.JFP $-11-059$.
42. Quinlan JJ. Foodborne illness incidence rates and food safety risks for populations of low socioeconomic status and minority race/ethnicity: a review of the literature. Int $\mathrm{J}$ Environ Res Public Health. 2013;10(8):363452. doi: 10.3390/ijerph10083634.

43. Vancouver Coastal Health. Food premises [Internet]. Vancouver (BC): Vancouver Coastal Health; [date unknown; cited 2017 Jan 26]. Available from: https://inspections.vcha.ca

44. Region of Waterloo. Public Health Inspection Results [Internet]. Waterloo (ON): Region of Waterloo; 2010 [cited 2017 Jan 26]. Available from: http:// www.region of waterloo.ca/en /safeHealthyCommunity/Public -Health-Inspection-Results.asp

45. Dollahite JS, Pijai EI, Scott-Pierce M, Parker C, Trochim W. A randomized controlled trial of a community-based nutrition education program for low-income parents. J Nutr Educ Behav. 2014;46(2):102-9. doi: 10.1016 /j.jneb.2013.09.004.

46. Gillespie IA, Mook P, Little CL, Grant KA, McLauchlin J. Human listeriosis in England, 2001-2007: association with neighbourhood deprivation. Euro Surveill. 2010;15(27):7-16.

47. Ahdoot S, Pacheco SE, The Council on Environmental Health. Global climate change and children's health. Pediatrics. 2015;136(5):e1-e17. doi: 10.1542/peds.2015-3233.

48. Province of British Columbia. Ministerial Order No. M217 [Internet]. Victoria (BC): Province of British Columbia; 2013 [cited 2017 Jun 30]. Available from: http://www.bclaws .ca/civix/document/id/mo/mo/2013 _m217/search/CIVIX_DOCUMENT_ ROOT_STEM:(environmental \% 20 health \%20officer)? 1 \#hit1

49. BC Food Security Gateway. Food security networks, policy councils, and agencies [Internet]. Vancouver (BC): Provincial Health Services Authority and the Public Health Association of BC; 2017 [cited 2017 Apr 13]. Available from: http:// bcfoodsecuritygateway.ca/about-bc -food-security-gateway/key-food -security-agencies/ 